\title{
Extra-ovarian production of mature viable mouse oocytes from frozen primary follicles*
}

\author{
J. Carroll, D. G. Whittingham, M. J. Wood, E. Telfer $\dagger$ and \\ R. G. Gosden $\dagger$ \\ MRC Experimental Embryology \& Teratology Unit, St. George's Hospital Medical School, \\ Cranmer Terrace, London SWI7 ORE, UK, and †Department of Physiology, Medical School, \\ University of Edinburgh, Edinburgh EH8 $9 A G, U K$
}

\begin{abstract}
Summary. Isolated primary mouse follicles can be frozen successfully and thawed in the presence of $1.5 \mathrm{M}$-DMSO. Similar proportions of freshly collected and frozen thawed primary follicles undergo folliculogenesis in the absence of other ovarian tissue. Some of the mature oocytes recovered from these follicles were fertilized in vitro and, after transfer to pseudopregnant recipients at the 2-cell stage, developed into live young. Cryopreservation and extra-ovarian development of immature follicles provide a unique opportunity to store large numbers of female gametes.
\end{abstract}

Keywords: cryopreservation; mouse; oocyte; primary follicle; in-vitro folliculogenesis; oocyte maturation; in-vitro fertilization; embryo transfer

\section{Introduction}

At birth the mammalian ovary contains many thousands of primordial follicles but the vast majority become atretic during their growth and maturation. As a result relatively few viable oocytes are produced during the reproductive lifespan of the female. The ability to rescue and preserve the pool of primary follicles offers a means of storing large numbers of female gametes. The successful preservation of mature ovulated oocytes with the subsequent birth of live young (Whittingham, 1977) was reported shortly after methods were devised for the storage of preimplantation mammalian embryos (Whittingham et al., 1972). Fully grown germinal vesicle-stage oocytes have a limited developmental capacity after freezing and thawing. Fragments of frozenthawed mouse ovarian tissue have yielded offspring after orthotopic transfer but success was limited (Parrott, 1960). With rat ovarian tissue only about $5 \%$ of the oocyte population appeared to survive freezing (Green et al., 1956) and none of these oocytes was contained in a follicle in an advanced stage of folliculogenesis (Deanesly, 1954).

The ovaries of 10-day-old mice contain a homogeneous population of primary follicles in the middle of their growth phase (Peters, 1969). Follicular development to the mature Graafian stage was obtained when disaggregated ovaries from this pre-natal stage were suspended in collagen gels and grown underneath the kidney capsules of ovariectomized mice (Torrance et al., 1988). Using a similar culture system we have demonstrated that isolated primary follicles grown in this site yield mature oocytes capable of fertilization in vitro and development to term (Carroll et al., 1989). Oocytes from the primary follicles of 12-day-old mice attain similar developmental potential after cultivation in vitro on collagen-coated membranes (Eppig \& Schroeder, 1989).

The ability to cryopreserve primary follicles would provide a valuable adjunct to these new techniques for obtaining folliculogenesis and oocyte development in extra-ovarian sites. The aim of this study was to assess the viability of oocytes derived from frozen-thawed primary follicles.

*Reprint requests to: Professor D. G. Whittingham. 


\section{Materials and Methods}

Follicle collection Ovaries were removed from 10-day-old B6CB (C57BL/6JLac $\times$ CBA/CaLac) F1 hybrid mice, bisected and incubated in a rolling culture system at $37^{\circ} \mathrm{C}$ in Medium M2 (Fulton \& Whittingham, 1978) containing $1.5 \mathrm{mg}$ collagenase $/ \mathrm{ml}$ (type 1: Sigma Chemical Co., Poole, Dorset, UK) and 40 units DNAse I/ml (Sigma). After $30 \mathrm{~min}$, the ovarian fragments suspended in $1 \mathrm{ml}$ of this medium were transferred to a watchglass containing $1 \mathrm{ml}$ Medium M2 supplemented with 5\% fetal calf serum (FCS: Flow Laboratories, Rickmansworth. Herts, UK) and disaggregated by manual pipetting. The disaggregated tissue was washed through 4 changes ( $2 \mathrm{ml}$ wash) of $\mathrm{M} 2+5 \%$ FCS. Using a fine-bore pipette, intact primary follicles containing an oocyte surrounded by 12 layers of granulosa cells were selected and pooled for freezing (Figs 1 and 2).

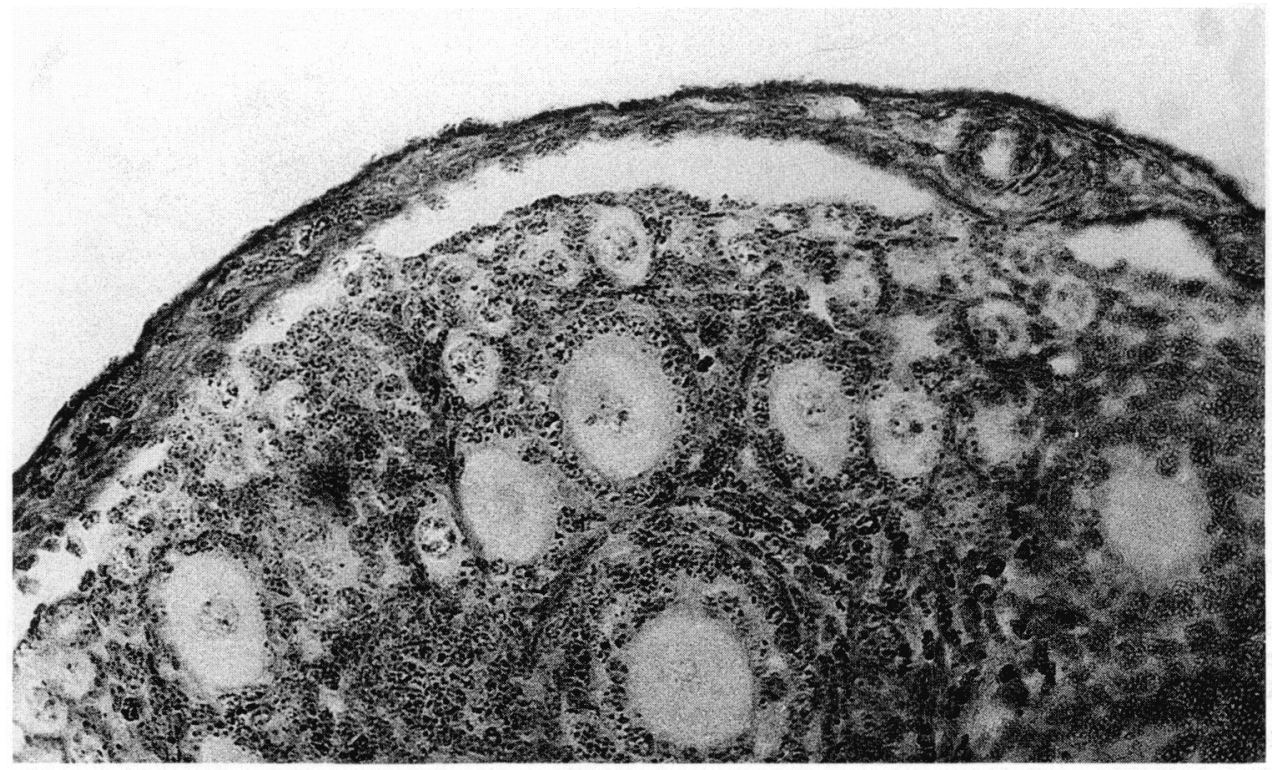

Fig. 1. Section through an ovary of a 10-day-old mouse. Primary follicles are surrounded by 1 or 2 layers of granulosa cells. $\times 1100$.

Freezing and thawing. The details of the freezing procedure have been described elsewhere (Carroll et al., 1989). Briefly, intact follicles were equilibrated at 0 C for $10-12 \mathrm{~min}$ in insemination straws $(0.25 \mathrm{ml}$; IMV, L'Aigle, France) containing DMSO $(1.5 \mathrm{M})$ in M2 $+10 \%$ FCS. Samples were seeded at $-7^{\circ} \mathrm{C}$ then cooled slowly $\left(0 \cdot 3^{\circ} \mathrm{C} / \mathrm{min}\right)$ to $-40^{\circ} \mathrm{C}$ before immersion in liquid nitrogen for storage at $-196^{\circ} \mathrm{C}$ for periods between 1 and 10 days. Samples were warmed rapidly $\left(\sim 2500^{\circ} \mathrm{C} / \mathrm{min}\right)$ and the DMSO diluted using $\mathrm{M} 2+10 \% \mathrm{FCS}$ in two steps at room temperature. Morphologically normal follicles with an intact oocyte surrounded by a continuous layer of granulosa cells were collected and suspended in collagen gels. Freshly collected follicles were treated similarly and used as controls.

Collagen gels. Collagen gel solution was prepared according to the methods of Torrance et al. (1989). To embed the isolated follicles in a collagen gel matrix, 50 follicles in $\mathrm{M} 2+5 \%$ FCS were placed in a well of a Terasaki plate (Flow Laboratories), excess medium was removed using a fine-bore pipette and $10 \mu 1$ collagen gel solution were added to the well. The follicles were suspended through the gel solution by gentle pipetting. The Terasaki plate was placed at $37 \mathrm{C}$ for 3-5 min to set the gel. Using fine forceps the gel was picked up and transferred to a well containing a further $20 \mu \mathrm{l}$ gel solution. The second gel was set as described above. The double gel served to protect the follicles during subsequent handling (Torrance et al., 1989).

Extra-ovarian development. The gels were cultured in MEM supplemented with 2 mm-glutamine, $0 \cdot 33$ mm-pyruvate, antibiotics and $10 \% \mathrm{FCS}$ at $37 \mathrm{C}$ in an humidified atmosphere of $5 \% \mathrm{CO}_{2}$ in air. After 6 days in vitro, the gels were transferred beneath the kidney capsules of 8-week-old female B6CBF1 mice which were ovariectomized in the same procedure. At 8 days after transfer, the recipients were given $7 \cdot 5$ i.u. pregnant mares' serum gonadotrophin (Folligon: Intervet, Science Park, Cambridge. UK) intraperitoneally, followed $48 \mathrm{~h}$ later by 5 i.u. human chorionic gonadotrophin (hCG; Chorulon: Intervet). The mice were killed 12-14 h after hCG and the collagen gels retrieved and dissected in $\mathrm{M} 2+5 \%$ FCS using forceps and sterile needles. Follicular cells were removed from the oocytes with a 


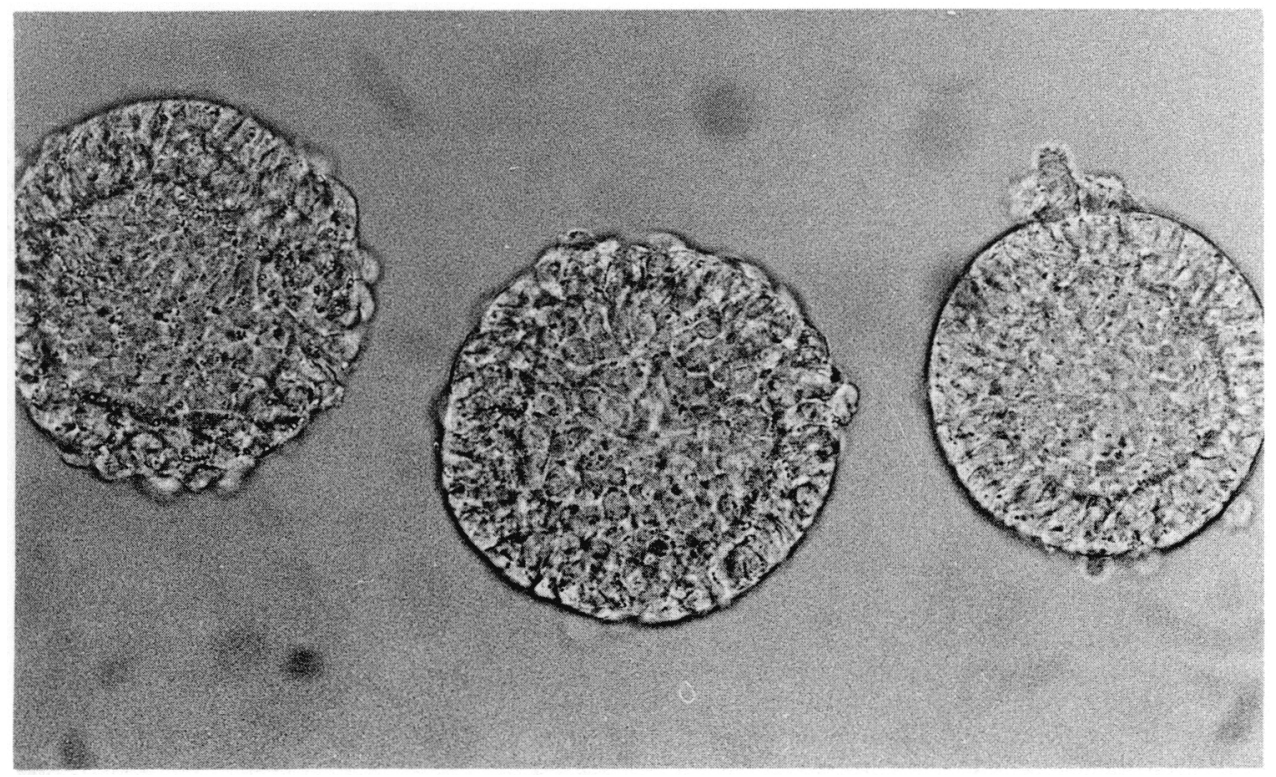

Fig. 2. Phase-contrast photomicrograph of primary follicles after isolation from the ovaries of a 10-day-old mouse. Each oocyte has an intact plasma membrane and is surrounded by several layers of granulosa cells. $\times 1100$.

fine-bore pipette or by hyaluronidase treatment (150 i.u./ml; Sigma). After washing in M $2+5 \%$ FCS the oocytes were counted and the stage of meiosis was noted. Oocytes recovered in the germinal vesicle stage were cultured in drops of Medium 16 (Whittingham, 1971) under light weight paraffin oil at $37^{\circ} \mathrm{C}$ in $5 \% \mathrm{CO}_{2}$ in air. Attempts were made to fertilize some of the oocytes recovered without a germinal vesicle or first polar body and some of the mature oocytes with a first polar body.

Fertilization in vitro and embryo transfer. The methods used for fertilization in vitro and embryo transfer have been described elsewhere (Glenister et al., 1987). Briefly, after incubation for $4 \mathrm{~h}$ with capacitated B6CBF1 spermatozoa $\left(1-2 \times 10^{6} / \mathrm{ml}\right)$ in Medium T6 (Quinn et al., 1982), oocytes were washed and cultured for $20 \mathrm{~h}$ in Medium 16. Oocytes that cleaved to the 2-cell stage were transferred to the oviducts of B6CBFl mice on Day 1 of pseudopregnancy. Pseudopregnancy was induced by mating with genetically sterile males heterozygous for translocation $\mathrm{T} 145 \mathrm{H}$. Recipient mice were allowed to litter or were autopsied on Day 15 of gestation to determine the total number of implantation sites and the number of fetuses.

\section{Results}

\section{Morphological survival of primary follicles after cryopreservation}

A total of 1425 isolated follicles were frozen. After thawing $1404(98 \%)$ of the follicles were recovered and $1097(78 \%$ ) were considered to be morphologically normal. In the remaining follicles the oocyte was lysed $(16 \%)$ and/or the granulosa cell layers were disrupted $(6 \%)$.

\section{Total number and stage of meiosis of oocytes recovered from collagen gels}

The number of oocytes recovered from the gels containing frozen-thawed follicles was similar to that from unfrozen controls (Table 1): 602 oocytes were recovered from 52 gels each of which contained 50 follicles at the beginning of culture. Follicular cells were removed from the oocytes to determine the stage of meiosis, namely: (1) germinal vesicle (GV); (2) germinal vesicle breakdown (GVBD); and (3) extrusion of the first polar body (Pbl). Similar proportions of oocytes at each stage of meiotic maturation were obtained from frozen-thawed and control follicles. Of all oocytes 
recovered, 7\% had extruded the first polar body (Fig. 3), 5\% had undergone GVBD, the majority of oocytes were recovered with a GV $(78 \%)$, and $10 \%$ of oocytes were degenerated.

\section{Developmental capacity of oocytes recovered from collagen gells}

$G \boldsymbol{V}$-stage oocytes. Oocytes at the germinal vesicle stage were generally recovered from dense masses of granulosa cells which were readily removed from the oocyte surface. After culture in vitro for $18 \mathrm{~h}$, there was no difference in the ability to resume meiosis or in the stage of meiosis reached between oocytes from control or frozen-thawed follicles. Of all GV stage oocytes cultured, $61 \%$ resumed meiosis and $42 \%$ extruded the first polar body (Table 2). No attempt was made to fertilize these oocytes.

GVBD-stage oocytes. Attempts were made to fertilize the 20 oocytes recovered from gels at the GVBD stage. Three cleaved to the 2-cell stage but further development was not examined.

Pb1 oocytes. Mature oocytes with the first polar body were released in an expanded matrix of follicular cells from large fluid-filled follicular structures. The oocyte-follicular cell complex was morphologically similar to the expanded cumulus mass obtained after natural ovulation and the follicular cells could be dispersed with hyaluronidase treatment. After release and dispersal of follicular cells, a small proportion of the mature oocytes from frozen and control groups were incubated with capacitated spermatozoa. Overall, 15 out of 25 oocytes were fertilized and cleaved to the 2-cell stage within $20 \mathrm{~h}$ of insemination (Table 3). After 10 two-cell embryos were transferred to pseudopregnant foster mothers, 4 out of 6 developed into liveborn young (Fig. 4 ) and 4 out of 4 implanted, 2 of which developed into live 15-day fetuses (Table 3). Fetuses and live young were obtained from the transfer of embryos derived from fresh and frozen-thawed primary follicles.

\section{Discussion}

The preservation of primary follicles provides a means of storing large numbers of the female gamete. Here we show that primary follicles can be frozen and thawed successfully and describe a system which allows their growth and maturation in extra-ovarian conditions. The resultant oocytes have the capacity to be fertilized in vitro and produce live young after transfer.

Primary follicles survive freezing at rates similar to those obtained previously for mature ovulated oocytes using the same freeze-thaw protocol (Carroll et al., 1989). The extensive damage to gametes in early attempts to cryopreserve ovarian tissue (Green et al., 1956; Parrott, 1960) may be explained by the use of freezing protocols developed before the discovery that rapidly permeating cryoprotectants and slow rates of cooling are essential for survival of these large mammalian cells (Whittingham et al., 1972). Cryopreservation of primary follicles requires not only the survival of the oocyte and granulosa cells but also maintenance of the gap junctions and metabolic cooperation essential for oocyte growth and development (Eppig, 1979; Brower \& Schultz, 1982; Herlands \& Schultz, 1984). Although oocyte survival could be determined using our morphological criteria it was not possible to assess the survival of individual granulosa cells or the state of gap junctions. The similarity of oocytes obtained after the development of frozen and control primary follicles indicates that granulosa cell-oocyte interaction was not irreversibly affected by freezing and thawing.

The large proportion of oocytes recorded in the GV stage indicates that the follicular response to gonadotrophins was sub-optimal since our histological evidence suggests that antrum formation in this system is limited (unpublished observations). Factors which may compromise follicular response are currently under investigation. These include: the absence of other ovarian tissue including theca and stroma, the high levels of gonadotrophins present in ovariectomized mice, or inadequate hormone stimulation because of poor vascularization in the extra-ovarian site. The observation that $61 \%$ of the GV stage oocytes were competent to resume meiosis and that two- 
Table 1. Stage of meiotic maturation of oocytes obtained from frozen thawed and control follicles after 16 days of extra-ovarian culture

\begin{tabular}{lcccccc}
\hline & \multirow{2}{*}{$\begin{array}{c}\text { No. of } \\
\text { gels }\end{array}$} & $\begin{array}{c}\text { No. of } \\
\text { oocytes }\end{array}$ & \multicolumn{4}{c}{ Stage of meiosis (\%) } \\
\cline { 5 - 7 } & recovered & GV & GVBD & Pbl & Degenerate \\
\hline Control & 27 & 311 & $247(79)$ & $17(5)$ & $23(7)$ & $24(8)$ \\
Frozen & 25 & 291 & $223(77)$ & $14(5)$ & $19(7)$ & $35(12)$ \\
Total & 52 & 602 & $470(78)$ & $31(5)$ & $42(7)$ & $59(10)$ \\
\hline
\end{tabular}

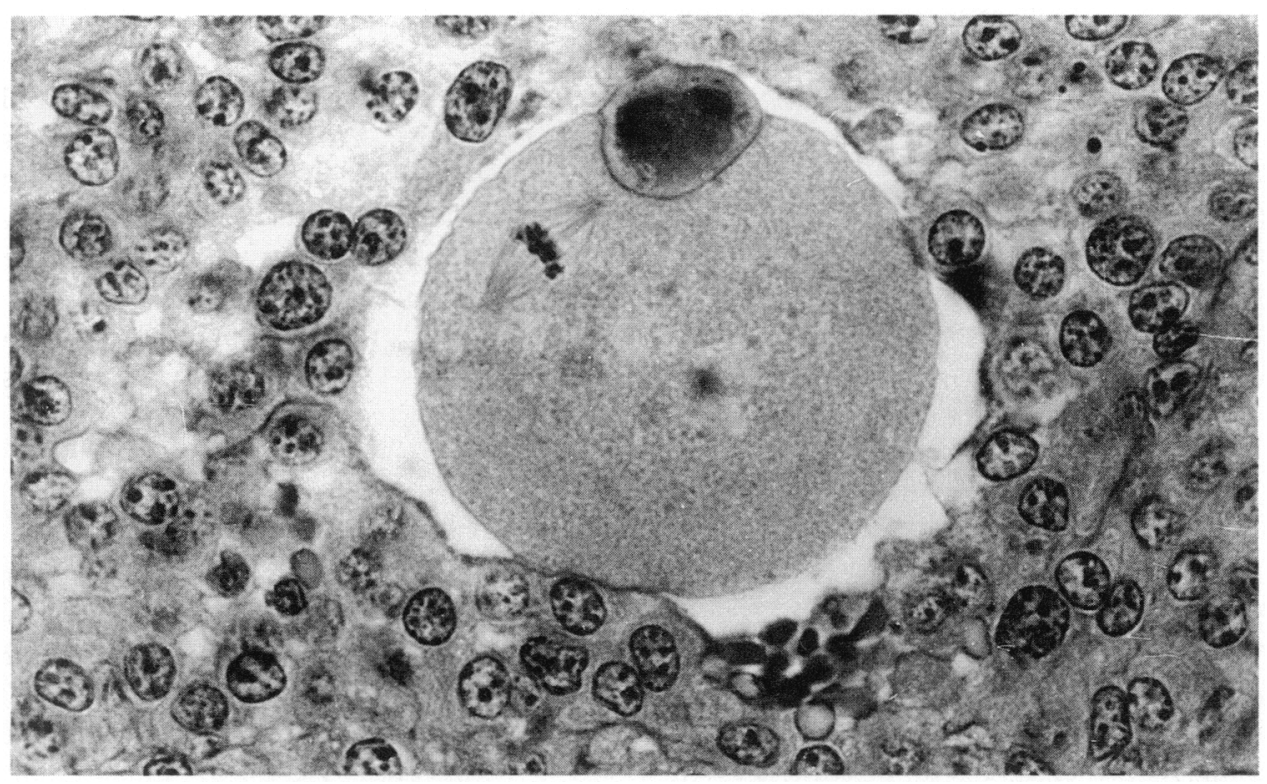

Fig. 3. Section through an oocyte from a follicle grown in a collagen gel matrix for 6 days in vitro then for 10 days underneath the kidney capsule of an ovariectomized mouse. The mouse was treated with gonadotrophin as described in 'Materials and Methods' and the gel recovered $12 \mathrm{~h}$ after hCG. The oocyte has extruded the first polar body and the chromosomes are arranged on the second meiotic spindle. A matrix of granulosa cells surrounds the oocyte. $\times 2700$.

Table 2. Resumption of meiosis in oocytes recovered from gels at the GV stage then cultured in vitro for $18 \mathrm{~h}$

\begin{tabular}{lcccccc}
\hline & $\begin{array}{c}\text { No. of GV } \\
\text { stage oocytes } \\
\text { cultured }\end{array}$ & \multicolumn{4}{c}{ Meiotic stage after culture (\%) } & $\begin{array}{c}\text { \% of oocytes } \\
\text { resuming } \\
\text { meiosis }\end{array}$ \\
\cline { 3 - 6 } & 173 & GV & GVBD & $\mathrm{Pbl}$ & Degenerate & \\
\hline Control & 170 & $51(30)$ & $32(18)$ & $73(42)$ & $28(16)$ & 61 \\
Frozen & 343 & $91(27)$ & $66(19)$ & $142(42)$ & $44(13)$ & 61 \\
Total & & & & &
\end{tabular}




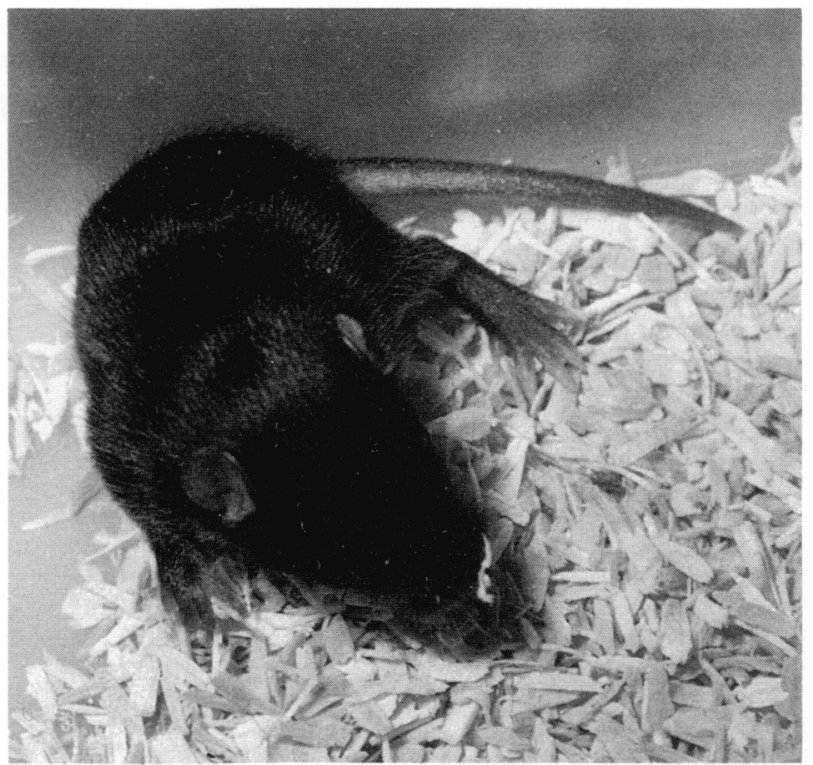

Fig. 4. Mouse born after the transfer of embryos derived from frozen-thawed primary follicles.

Table 3. Fertilization in vitro of oocytes recovered with the first polar body and development after transfer to pseudopregnant recipients

\begin{tabular}{|c|c|c|c|c|c|c|}
\hline & \multirow{2}{*}{$\begin{array}{c}\text { No. of } \\
\text { oocytes } \\
\text { inseminated }\end{array}$} & \multirow{2}{*}{$\begin{array}{c}\text { No. of } \\
\text { 2-cell } \\
\text { embryos }\end{array}$} & \multirow{2}{*}{$\begin{array}{l}\text { No. of } \\
\text { embryos } \\
\text { transferred }\end{array}$} & \multicolumn{2}{|c|}{$\begin{array}{c}\text { Autopsy on Day } 15 \\
\text { of gestation }\end{array}$} & \multirow[b]{2}{*}{$\begin{array}{l}\text { No. of } \\
\text { liveborn }\end{array}$} \\
\hline & & & & $\begin{array}{c}\text { No. of } \\
\text { implantations }\end{array}$ & $\begin{array}{l}\text { No. of } \\
\text { fetuses }\end{array}$ & \\
\hline Control & 15 & 10 & $\begin{array}{l}2 \\
4\end{array}$ & 2 & 1 & $\overline{3}$ \\
\hline Frozen & 10 & 5 & $\begin{array}{l}2 \\
2\end{array}$ & 2 & 1 & 1 \\
\hline
\end{tabular}

thirds of these reached full meiotic maturation indicates that these isolated follicles were capable of maintaining meiotic arrest. The developmental capacity of these oocytes was not determined but may provide a possible source of gametes in the future. This possibility is supported by the recent observation that live young can be obtained after the transfer of embryos derived from oocytes grown, matured and fertilized in vitro (Eppig \& Schroeder, 1989).

The reason for the high rate of atresia in extra-ovarian development is unclear although a high rate of atresia occurs in the ovaries of pre-pubertal mice (Peters, 1969). Therefore it is not unreasonable to assume that some of the follicles selected for culture were already committed to atresia. Components of the extra-ovarian culture system may also have contributed to follicular loss, e.g. (1) irreversible damage during isolation, (2) sub-optimal culture conditions, (3) restricted supply of hormones and nutrients to gels underneath the kidney capsule, (4) high concentrations of gonadotrophins present in ovariectomized mice, (5) absence of other ovarian tissue during development.

Nevertheless, we have shown that it is feasible to cryopreserve isolated primary follicles for subsequent growth and maturation in the absence of other ovarian tissue. Further, mature oocytes 
derived from frozen-thawed and control primary follicles have the capacity to be fertilized and develop to live young after transfer. With improvements in culture systems for extra-ovarian follicular development the low temperature storage of ovarian follicles will make a valuable contribution to the conservation of rare breeds and endangered species, agricultural efficiency, human reproductive medicine and basic research in folliculogenesis.

We thank Professor C. D. Matthews for provision of a Reproductive Medicine Postgraduate Scholarship to J.C.

\section{References}

Brower, P.T. \& Schults, R.M. (1982) Intercellular communication between granulosa cells and mouse oocytes: existence and possible nutritional role during oocyte growth. Devl Biol. 90, 144-153.

Carroll, J., Warnes, G.M. \& Matthews, C.D. (1989) Increase in digyny explains polyploidy after in-vitro fertilization of frozen-thawed mouse oocytes. $J$. Reprod. Fert. 85, 489-494.

Carroll, J., Wood, M.J., Whittingham, D.G., Telfer, E. \& Gosden, R.G. (1989) Growth and development of mouse immature follicles. J. Reprod. Fert., Abstr. Ser. 3, 18, abstr.

Deanesly, R. (1954) Immature rat ovaries grafted after freezing and thawing. J. Endocr. 11, 197-200.

Eppig, J.J. (1979) A comparison between oocyte growth in co-culture with granulosa cells and oocytes with granulosa cell-oocyte junctional contact maintained in vitro. J. exp. Zool. 209, 345-353.

Eppig, J.J. \& Schroeder, A.C. (1989) Capacity of mouse oocytes from pre-antral follicles to undergo embryogenesis and development to live young after growth, maturation and fertilization in vitro. Biol. Reprod. 41, 268-276.

Fulton, B.P. \& Whittingham, D.G. (1978) Activation of mammalian oocytes by intracellular injection of calcium. Nature. Lond. 273, 149-151.

Glenister, P.H., Wood, M.J., Kirby, C. \& Whittingham, D.G. (1987) Incidence of chromosome anomalies in first-cleavage mouse embryos obtained from frozenthawed oocytes fertilized in vitro. Gamete Res. 16, 205-2I6.

Green, S.H., Smith, A.U. \& Zuckerman, S. (1956) The numbers of oocytes in ovarian autografts after freezing and thawing. J. Endocr. 13, 330-334.
Herlands, R.L. \& Schultz, R.M. (1984) Regulation of mouse oocyte growth: probable nutritional role for intercellular communication between follicle cells and oocytes in oocyte growth. J. exp. Zool. 229, 317-325.

Parrot, D.M.V. (1960) The fertility of mice with orthotopic ovarian grafts derived from frozen tissue. $J$. Reprod. Fert. 1, 230-241.

Peters, H. (1969) The development of mouse ovary from birth to maturity. Acta endocr., Copenh. 62, 98-116.

Quinn, P., Barros, C. \& Whittingham, D.G. (1982) Preservation of hamster oocytes to assay the fertilizing capacity of human spermatozoa. J. Reprod. Fert. 66, 161-168.

Torrance, C., Telfer, E. \& Gosden R.G. (1988) An investigation of mouse ovarian follicles in collagen gel culture. J. Reprod. Fert., Abstr. Ser. 1, 24, abstr.

Torrance, C., Telfer, E. \& Gosden R.G. (1989) Quantitative study of the development of isolated mouse preantral follicles in collagen gel culture. J. Reprod. Fert. 87, 367-374.

Whittingham, D.G. (1971) Culture of mouse ova. $J$. Reprod. Fert., Suppl. 14, 7-21.

Whittingham, D.G. (1977) Fertilization in vitro and development to term of unfertilized mouse oocytes previously stored at $-196^{\circ} \mathrm{C}$. J. Reprod. Fert. 49, 89-94.

Whittingham, D.G., Leibo, S.P. \& Mazur, P. (1972) Survival of mouse embryos frozen to $-196^{\circ} \mathrm{C}$ and $-269^{\circ}$ C. Science, N.Y. 187, $411-414$.

Received 12 February 1990 